\title{
Assessment on passive cooling techniques to improve steel roof thermal performance in hot tropical climate
}

\author{
Madi Kabore $^{1,2}$, Etienne Wurtz ${ }^{3}$, Yézouma Coulibaly ${ }^{1}$, Adamah Messan $^{1}$, Patrice Moreaux ${ }^{2}$ \\ ${ }^{1}$ International institute for water and environmental engineering (2iE), Ouagadougou, Burkina Faso \\ ${ }^{2}$ University Savoie Mont Blanc, Chambéry, France \\ ${ }^{3}$ University Grenoble Alpes, INES, Le Bourget du Lac, France
}

Email address:

Madi_kabore@outlook.com (M. Kabore)

\section{To cite this article:}

Madi Kabore, Etienne Wurtz, Yézouma Coulibaly, Adamah Messan, Patrice Moreaux. Assessment on Passive Cooling Techniques to Improve Steel Roof Thermal Performance in Hot Tropical Climate. International Journal of Energy and Power Engineering.

Vol. 3, No. 6, 2014, pp. 287-295. doi: 10.11648/j.ijepe.20140306.12

\begin{abstract}
In African hot tropical climate countries, due to climate and the unsuitability of construction materials, building's indoor environment remains over the thermal comfort acceptable limit over long periods of time during the year. Among the building envelope components, roof is a critical part that is highly susceptible to solar radiation. Solutions like passive cooling and low energy consumption systems are not explored enough in those countries. These techniques and systems can be used to meet a large part of the cooling needs and reduce the overheating period in buildings, but their applicability depends on the climate zone. In this paper, investigations were conducted to determine their potential to improve steel roof performance for free running buildings under tropical climatic conditions. The case studies are two configurations (with and without attic) of typical steel roof in Burkina Faso. Using dynamic simulation, we have evaluated the impacts of radiant barrier, insulation, cool paint and ventilation for two configuration of roofing. For both configurations, high reflective solutions perform very well. It also appears that the attic case due to its actual configuration (shape and design) and to the climate conditions ventilation does not perform very well. These results can help building actors during the design process.
\end{abstract}

Keywords: Free Running Building, Passive Cooling, Cool Roof, Steel Roof, Hot Tropical Climate

\section{Introduction}

During the 19th century, Africa has been the subject of socio-cultural changes. These changes have impacted the construction sector with the adoption of new techniques from developed countries [1-3]. New materials, buildings architectures and the building policies have been adopted to respond to the lack of vernacular architecture with no regard to energy consumption and environmental challenges. The result is a poorly adapted to its climatic context habitat. This situation is accentuated in areas where the tropical wet and dry climate prevails. In these regions the contemporary buildings need more energy to supply the comfort needs. Bioclimatic design, ecological and passive cooling techniques are poorly explored solutions.

For [3] new construction technologies changed the face of African housing and its aspirations, firstly in the choice of construction materials and secondly, in the fitness of the dwelling and consequently the occupant's behavior. He also denoted that one of the most adopted materials is metal sheet as roof material due to its cost and its easiness to use. In fact, domed and vaulted roof made from starch and earthen made flat roof have [4] been replaced by steel roofing.

Table 1. Survey on roofing materials in Burkina Faso (\%) (Insd)

\begin{tabular}{llllll}
\hline & Year & Straw/wood & Metal sheet & Earthen & Other \\
\hline \multirow{4}{*}{ Burkina Faso } & 2003 & 30.2 & 41.1 & 27.8 & 0.9 \\
& 2006 & 26.5 & 45.7 & 26.9 & 0.9 \\
& 2007 & 27.1 & 48.6 & 22.6 & 1.6 \\
Kadiogo & 2003 & 5.5 & 92.2 & 0.6 & 1.7 \\
& 2006 & 2.2 & 94.8 & 0.1 & 2.9 \\
& 2007 & 3.2 & 90.9 & 1.2 & 4.8 \\
\hline
\end{tabular}

A recent survey in 2007 in Burkina Faso by INSD $^{1}$ (Table 1) confirmed the finding of [3]. In Burkina Faso the half of the buildings has metal roofs but in Kadiogo, the most developed area in the country the rate is $90 \%$.

Among all components of a building envelope that are in

${ }^{1}$ National Demographic Institute Burkina Faso 
contact with the external environment conditions, a roof due to its tilt, is the most exposed component particularly to solar radiation. It plays an important role in the thermal performance of buildings by radiating towards other components or by convection heat transfer mode to air [5]. Reference [6], noted that a roof can contribute with up to $50 \%$ of the thermal load for buildings in hot climates.

Decreasing the temperature of roof and other opaque components reduces the heat flow into the building, leading to energy savings in air conditioned buildings and reduces also overheating periods in free-running ones [7-10]. Several strategies exist to reduce the roof part on building indoor environment heat gain. Among these methods, there are roof's passive cooling techniques that [11] classified in architectural and non-architectural methods. The architectural methods are related to the configuration and the roof geometry that contribute to the reduction of heat gains. These methods such as vaulted, domed, or naturally ventilated roofs are, are usually applied during the construction stage of the buildings. The non-architectural methods (radiant barriers, insulation, multiple skin, and shading) can be used independently of the roof geometries.

Concerning the ventilation, airflow through the building envelope is a factor influencing heat loss/gain and moisture transfer. The ventilation of a roof or an attic has become one of the greatest interests for building researchers during the last decades. Ventilation of an attic has traditionally been practiced to decrease its temperature in order to reduce the cooling load of the occupied space and to evacuate moisture. In [12] comparisons have been made between a cavity roof and a simple single roof in factories in Japan. Results showed that the cavity roof was better than the single roof in lowering the operative temperature by about $4.4^{\circ} \mathrm{C}$ and enhanced the life time of air conditioning system by reducing the cooling load.

Reference [9], in a review focused on solar reflective roofs analyzed a large number of studies on test cells, building simulations, and on numerical methods to evaluate the roof performance. These studies have shown that cool materials are appropriate for warm climates; the warmer the climate is, the higher are the energy savings. In addition, many of the simulation studies conclude that energy savings are more important in poorly insulated buildings. Reference [13] denoted that literature indicated that the peak cooling energy savings from cool roofs in the USA are between $3 \%$ and $35 \%$, which depends on ceiling insulation levels, and attic configuration. Reference [14] investigated to find the type of roof that can enhance thermal comfort in a warm climate like the case of Gazimagusa in Turkey. In his paper he reports that the roofs with thermal insulation (depending on location) show the best performance. It also appears that the reflectance of outside surface materials affects significantly the thermal performance.

In some countries, such as the USA and Australia thermal radiation barriers are widely employed in buildings and there are norms on technical specifications [15]. Radiant barriers consist of a highly infrared reflective material, usually aluminum foil, which is applied to one or both sides of a number of substrate materials such as craft paper, plastic films. For example, in 1967, aluminum foil was used in house roofs in Australia with the polished side facing downward [16].

In summary these passive techniques and systems can be used to meet a large part of cooling needs and reduce the overheating period in buildings, and their applicability and performance depend on the climate zone. Indeed sub-Saharan Africa, passive cooling techniques and low energy consumption systems are not explored enough. The lack of building energy regulation and policy reported by [17] in these regions can explain this finding. There is also a lack of literature regarding the performance of roof in the African climates. This paper aims to evaluate ways to improve thermal performances of existing steel roof arrangements in a hot tropical climate by passive cooling techniques. For that purposes architectural (air gap and natural ventilation) and non-architectural (reflective coating, radiant barrier and insulation) solutions have been evaluated for a typical roof in Burkina Faso using whole building simulations.

\section{Methodology and Simulation}

\subsection{The Reference Case}

The case study is a single family dwelling of Burkina Faso (Figure 1). The walls are made of hollow cement blocks and the roof with red coated galvanized iron sheets. The building lies in an urban area and the entry is oriented $328^{\circ} \mathrm{N}$. There is no insulation or attic in this reference simple roof case. On field measurements have been conducted from $21^{\text {st }}$ to $27^{\text {th }}$ February 2014. Figure 2 presents the meteorological data of Ouagadougou during the experimental period. The region is a high solar radiation region with low wind speed. These data have been used as input for the simulation program.

\subsection{Roof Configuration}

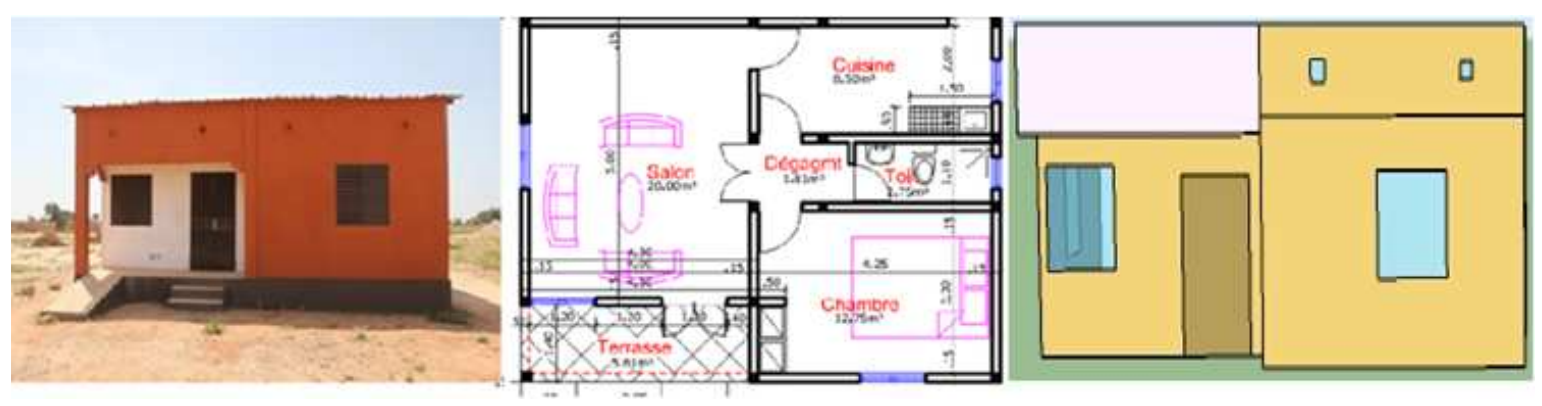

Figure 1. The studied building (A), the plan (B) and the EnergyPlus model $(C)$. 

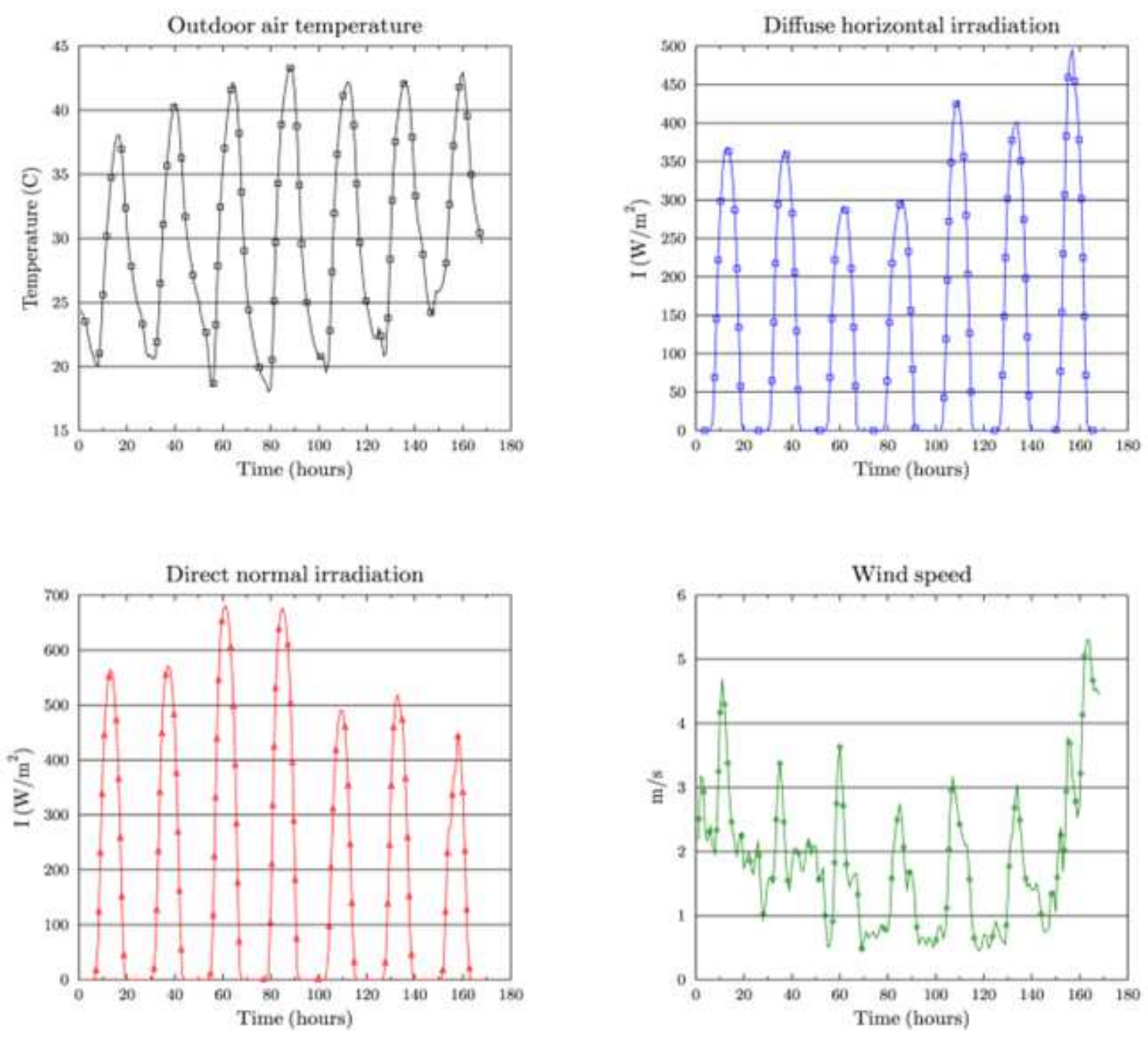

Figure 2. Meteorological data.

In order to evaluate the impact of passive cooling strategies on indoor environment several configurations of the roof have been provided to the building model (Figure 1). Two main configurations of steel roof are present in Africa tropical and subtropical countries. There is the case where the steel roof inside face is a part of the occupied zone surface. The other case is an improvement of the first. This case consists of steel roof, air gap and plywood. This is the attic case. The ventilation consists of eight openings $(10 \mathrm{~cm}$ diameter $)$ in front and backside of the building. The size of the opening is not a result of design but let to the choice of the builder. The first case is a popular strategy that we can find in hot tropical area. Investigations have been conducted to improve these cases with architectural and non-architectural solutions. For architectural solutions the natural ventilation has been modeled for the attic case. Cool paint, inside insulation layer for the two cases and radiant barrier constitute the non-architectural solutions simulated here.

\subsection{Simulation Tools}

EnergyPlus [18] is used for the simulation. It is one of the most used building energy simulation tools in the world. It allows the simulation of thin envelope components such as metal roof by applying the Conduction Transfer Function
(CTF) method to solve the problem. The sky radiance distribution is based on an empirical model based on radiance measurements of real skies, as described in [19]. The TARP algorithm [20] has been used to evaluate convective heat transfer coefficient of the building surfaces.

The optical and thermal properties of the building model are summarized in Table 2 and 3. For the case of attic, the building is modeled in two zones. The attic zone is a $1 \mathrm{~m}$ height zone and has the plywood as a floor. The occupied zone sees the floor of the attic zone as a ceiling. Another model of the building is also implemented to assess the case of simple roof without attic.

The roof openings are modeled as windows of this zone. These openings are positioned on front and backsides of the attic faces, so a cross ventilation will occur in the attic. Several methods (empirical, networks, zonal and computational fluid dynamics) exist to predict the air flow rate [21]. For this study, the British standard which is an empirical method (equation 1 and 2) has been used to assess ventilation impacts on the roof behavior for cross ventilation of the roof. The discharge coefficient is set to be 0.6 [22]. The pressure coefficients are averaged values computed by the program for a rectangular low rise building by using Swami and Chandra method (equation (4)) [20]. For the experimental building, we have 
four openings on each side. As suggested by [23] in a case of multiple opening with the same area, the equivalent area is equal to the sum for parallel configuration and to the sum of their inverses in series configuration. The British standard formulas for cross ventilation with the same area on each opposite side become:

$$
\begin{gathered}
\text { for } \frac{\mathrm{V}}{\sqrt{\Delta \mathrm{T}}}<0.26 \sqrt{\frac{\mathrm{H}}{\Delta \mathrm{C}_{\mathrm{p}}}} \quad \mathrm{Q}=\mathrm{c}_{\mathrm{d}} \mathrm{AV} \sqrt{\Delta \mathrm{C}_{\mathrm{p}}} \\
\text { for } \frac{\mathrm{V}}{\sqrt{\Delta \mathrm{T}}}<0.26 \sqrt{\frac{\mathrm{H}}{\Delta \mathrm{C}_{\mathrm{p}}}} \quad \mathrm{Q}=\mathrm{c}_{\mathrm{d}} \mathrm{A} \sqrt{2 \mathrm{gH} \frac{\left|\mathrm{T}_{\mathrm{i}}-\mathrm{T}_{\mathrm{o}}\right|}{\left(\mathrm{T}_{\mathrm{i}}+\mathrm{T}_{\mathrm{o}}\right) / 2}}
\end{gathered}
$$

$\mathrm{C}_{\mathrm{p}}$, the discharge coefficient; $\mathrm{A}$, the equivalent area of openings; $\mathrm{C}_{\mathrm{p}}$, the pressure coefficient; $\mathrm{T}_{\mathrm{I}} \mathrm{T}_{\mathrm{o}}$, indoor and outdoor temperatures; $\mathrm{V}$, the reference wind speed; $\mathrm{H}$, height between the opposites openings.

$$
\mathrm{V}=\mathrm{V}_{\text {met }}\left(\frac{\mathrm{z}_{\mathrm{a}}}{\mathrm{z}_{\mathrm{met}}}\right)^{\alpha}
$$

With $\mathrm{V}_{\text {met }}$, the wind speed of meteorological station sensor; $\mathrm{z}_{\text {met }}$, the height of the meteorological station wind speed sensor; $\alpha$, the roughness type ( 0.4 for urban areas).

$\mathrm{C}_{\mathrm{P}, \mathrm{n}}=0.6 \operatorname{Ln}\left(1.248-0.703 \sin \left(\frac{\alpha}{2}\right)-1.175 \sin ^{2}(\alpha)+0.131 \sin ^{3}(2 \alpha \mathrm{G})\right.$

$$
+0.769 \cos \left(\frac{\alpha}{2}\right)+0.07 \mathrm{G}^{2} \sin ^{2}\left(\frac{\alpha}{2}\right)+0.717 \cos ^{2}\left(\frac{\underline{\alpha}}{2}\right)
$$

With $\mathrm{C}_{\mathrm{P}, \mathrm{n}}$, value at a given angle between wind direction and the outward normal of the surface; $\alpha$, here, angle between wind direction and outward normal of wall under consideration; $G$, natural $\log$ of the ratio of the width of the wall under consideration to the width of the adjacent wall; $n$, Index of incident angle at 30-degree increments.

The model is implemented in Dymola, a Modelica based environment in order to export it in FMI [24] format and link to EnergyPlus by co-simulation [25]. At each time step both models run in different environments and data are exchanged. Between times steps EnergyPlus sends information on the attic mean air temperature, outdoor dry bulb temperature, the area of the opening and pressure coefficients, when Fmu computes the next step zone flow rate and writes it to Energy Plus (Figure 3).

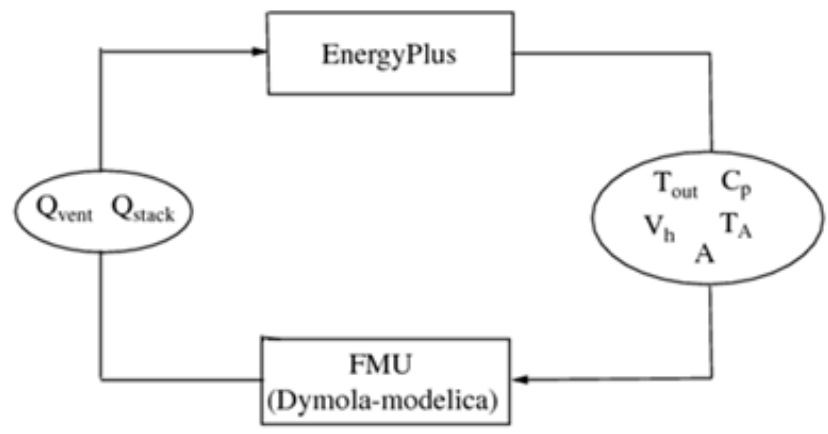

Figure 3. Co-simulation EnergyPlus and Dymola using FMU
Table 2. Long wave emissivity and short wave absorptivity

\begin{tabular}{lll}
\hline & Long wave emissivity & Short wave absorptivity \\
\hline white paint & 0.9 & 0.26 \\
Aluminum foil & 0.03 & 0.10 \\
reference coating & 0.9 & 0.45 \\
\hline
\end{tabular}

Table 3. Thermal properties of materials

\begin{tabular}{llll}
\hline Material & $\begin{array}{l}\text { Conductivity } \\
\left(\mathbf{W} / \mathbf{m}^{\circ} \mathbf{K}\right)\end{array}$ & $\begin{array}{l}\text { Specific heat } \\
(\mathbf{J} / \mathbf{k g} . \mathbf{K})\end{array}$ & $\begin{array}{l}\text { Density } \\
\left(\mathbf{K g} / \mathbf{m}^{3}\right)\end{array}$ \\
\hline Galvanized steel & 50 & 480 & 7800 \\
Concrete & 1.4 & 840 & 2240 \\
Hollow cement brick & 0.833 & 1000 & 1000 \\
Plywood & 0.15 & 500 & 1200 \\
Plaster & 1.15 & 1000 & 1700 \\
Glass fiber & 0.04 & 840 & 12 \\
\hline
\end{tabular}

\section{Results and Discussion}

\subsection{Validation of the Roof Model}

The field survey has been conducted on the typical family building using PT100 sensors. The building has been closed (doors and windows) during the measurement period. The building was not occupied and there is no heat source. The sensors are of PT100 type with a memory permitting the storage of data. The inside face temperatures of the opaque surfaces and roof are measured by contact with sensors of TG type from Waranet having a precision of $0.36^{\circ} \mathrm{C}$.

Here we focused on the roof inside face temperature and the results are shown in Figure 4. We can observe that the temperature at noon is very high when the level of solar radiation is also high. At night, the roof is cooled by air convection and radiative heat transfer with the sky. For comparing measured and simulated data, the ASTM Standard D5157 and ASHRAE method [26] was used. The line of regression (Figure 5) meets the requirements as the coefficient of predictions is greater than 0.9 and the slope of the line is between 0.75 and 1.25 . The model of the roof represents well the field measurements. So this model is then used to evaluate the effects of passives solutions by simulation.

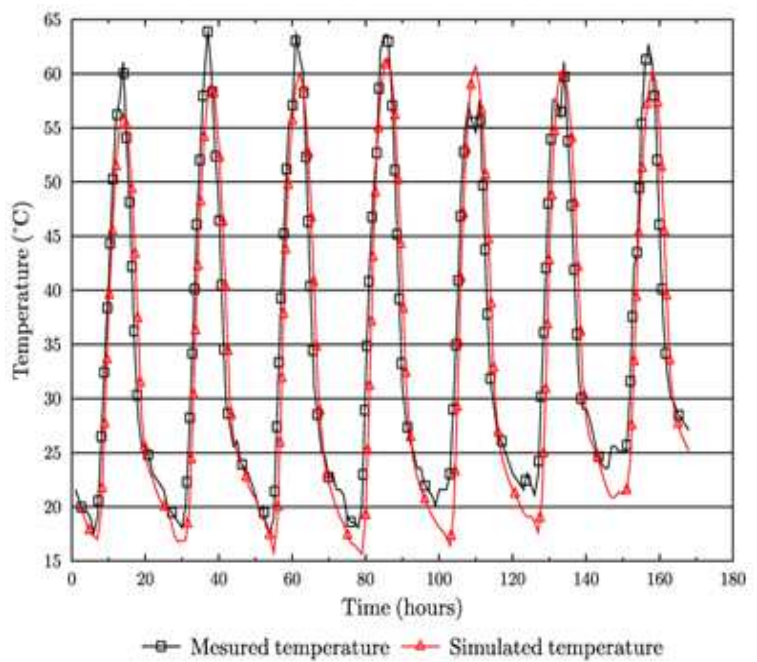

Figure 4. Comparison between measured and simulated roof inside face temperature. 


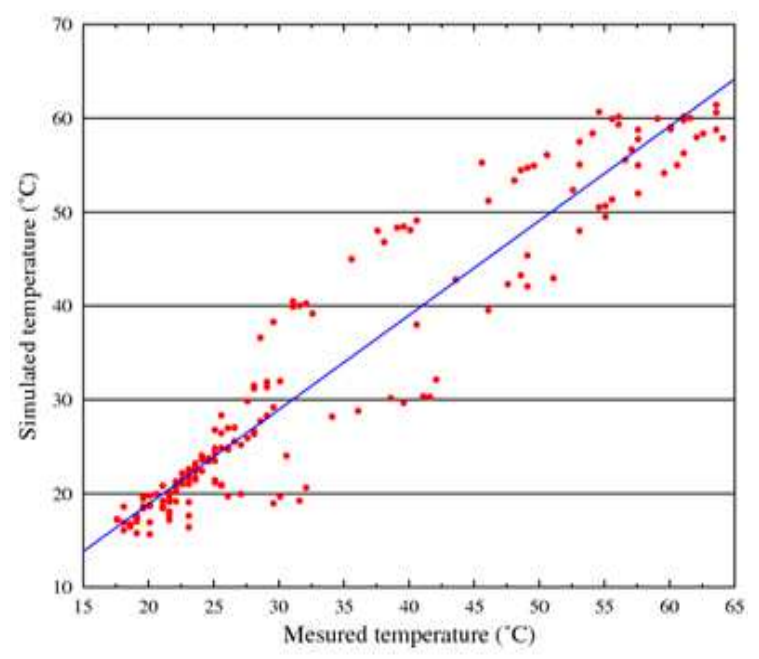

Slope $=1.01$, Offset $=-1.26, R^{2}=0.919$

Figure 5. Validation of roof inside face temperatures.

\subsection{Comparison between the Two Reference Configurations}

Comparison between the attic and the simple steel roof configurations are shown in Figure 6 and 7. The attic consists of an air gap and $5 \mathrm{~mm}$ plywood. One can observe that the ceiling inside face temperatures (Figure 6) and the occupied zone air temperatures (Figure 7) are amortized for the attic case compared to reference simple roof case. During daytime, the occupied zone temperatures in the attic case (Figure 7) decrease but during nighttime these temperatures are higher than the simple steel case. This situation is due to the fact that the plywood and the air gap eliminate the cooling effect of roof on the zone at night. To compare these two configurations, the decrement factor $\mathrm{f}$ and the time lag $\Phi$ are expressed relative to simple roof case and evaluated by equation (5) and (6). Indeed for a day type, one can observe a decrement factor of 4.7 and a time lag between the two peaks of approximately $2 \mathrm{~h}$ between the temperatures of the inside face of the roof and the ceiling.

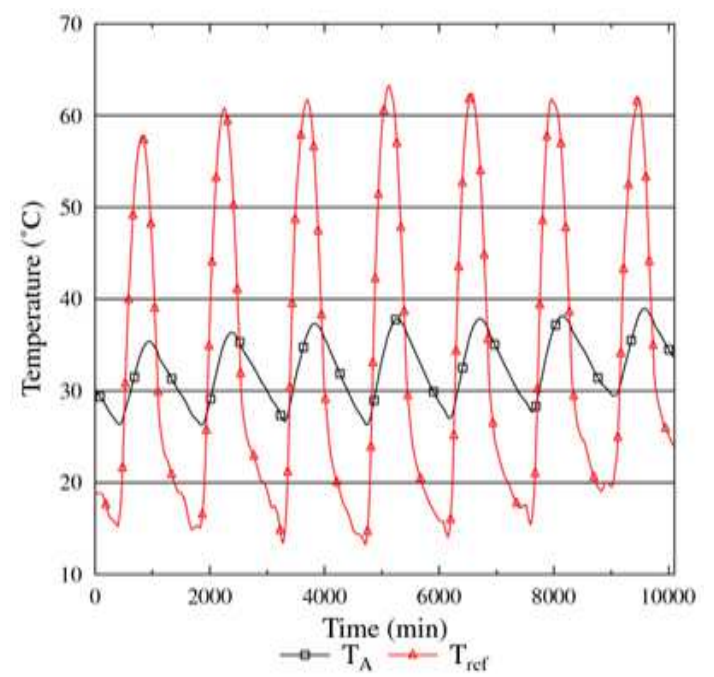

Figure 6. Roof inside face temperature for simple roof case and ceiling inside face temperature for reference attic case

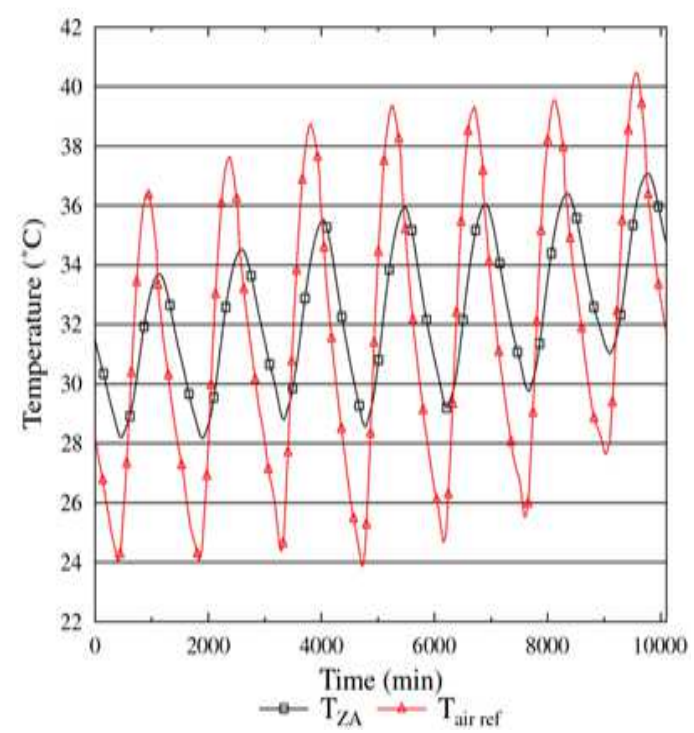

Figure 7. Occupied zone air mean temperature for simple roof case and reference attic case

$$
\begin{gathered}
\mathrm{f}=\frac{\operatorname{Max}\left(\mathrm{T}_{\mathrm{ref}}\right)-\operatorname{Min}\left(\mathrm{T}_{\mathrm{ref}}\right)}{\operatorname{Max}\left(\mathrm{T}_{\mathrm{A}}\right)-\operatorname{Min}\left(\mathrm{T}_{\mathrm{A}}\right)} \\
\Phi=\mathrm{t}_{\operatorname{Max}\left(\mathrm{T}_{\mathrm{A}}\right) \mathrm{t}_{\operatorname{Max}}\left(\mathrm{T}_{\mathrm{ref}}\right)}
\end{gathered}
$$

With $\mathrm{T}$, the temperature of roof inside face and $\mathrm{t}$ is the time.

Considering the properties of air, it is known that this space will behave as an insulation layer. The air space eliminates the impact of the cooled roof on the occupied zone during the nocturnal hours. This explains high ceiling temperatures during the night for the attic case.

\subsection{Natural Ventilation as an Architectural Solution}

For the existing case of attic ventilation, the flow rate is negligible. In fact the attic's openings attic are small and on the same level for the existing case $(\mathrm{H}=0)$, so a wind driven flow will be computed according to British standard formula. This configuration does not enhance buoyancy effect.

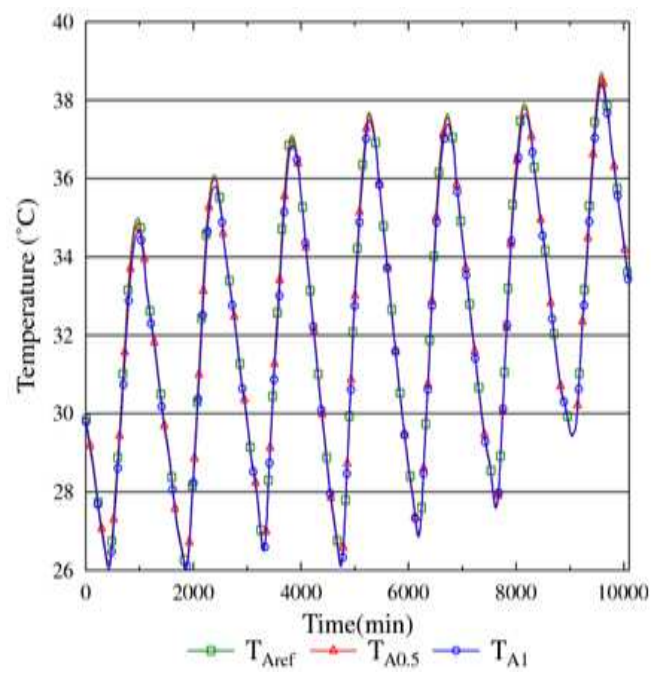

Figure 8. Occupied zone side ceiling temperature for different opening equivalent sizes. 
A parametric study was carried out on the attic's openings size and the height between the opposite sides groups of openings in order to improve the ventilation. Figure 8 summarizes the results when $\mathrm{H}=0$ for different opening equivalent areas $\left(\mathrm{T}_{\mathrm{Aref}}, \mathrm{T}_{\mathrm{A} 0.5}\right.$ and $\mathrm{T}_{\mathrm{Al}}$, for initial, $0.5 \mathrm{~m}^{2}$ and $1 \mathrm{~m}^{2}$ respectively). The ceiling temperature (Figure 8) decreases when the openings equivalent area increases meaning a high ventilation rate. These differences are not significant. This is due to the fact that outdoor air temperature can be higher than the attic air temperature. So this does not help reducing the temperature of the plywood ceiling.

\subsection{Evaluation of Non-Architectural Solutions}

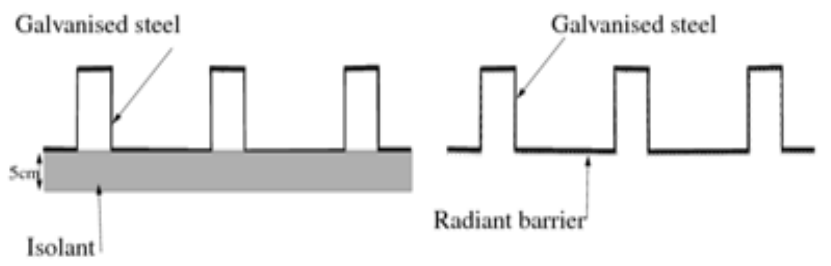

(a) Insulation case

(b) Radiant barrier case

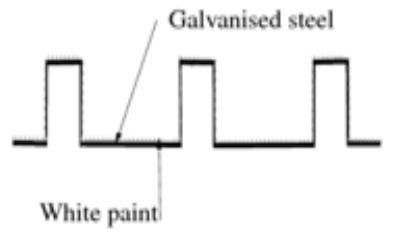

(c) Cool paint case

Figure 9. Illustration of simple roof cases.

Three solutions (radiant barrier, insulation, and white paint as a reflective coating) are shown in this party (Figure 9 and Figure 12). The improvements due to these solutions have been evaluated for the two cases (with and without attic). Reflective cool roof solutions have been modeled by using the optical properties of the white paint (Table 3). The insulation option consists of $5 \mathrm{~cm}$ of glass fiber applied on the inside face of the steel roof in the simple roof case and on the plywood in the attic. The radiant barrier consists of a layer of aluminum foil which has a high infrared reflectance (Table 3).

\subsubsection{Case of Roof without an Attic}

Figure 10 and 11 show the inside face temperature of the roof and the occupied zone air temperature. Table 4 resumes the decrement factor and time lag in these cases. There is no great difference between the case with radiant barrier and the reference case for roof temperatures (Figure $10 \mathrm{~T}_{\text {rad }}$ and $\mathrm{T}_{\text {ref }}$ ) and occupied zone air temperatures $\left(\mathrm{T}_{\mathrm{Zrad}}\right.$ and $\left.\mathrm{T}_{\mathrm{Zref}}\right)$. The low long wave emissivity of the radiant barrier can explain the small difference observed $(\mathrm{f}=0.96)$ in roof temperature. For the zone air temperature, the radiant barrier case is a slightly lower than the reference one for daytime hours.

These small differences of roof temperatures mean weak changes in occupied zone air temperatures as observed in Figure 11.

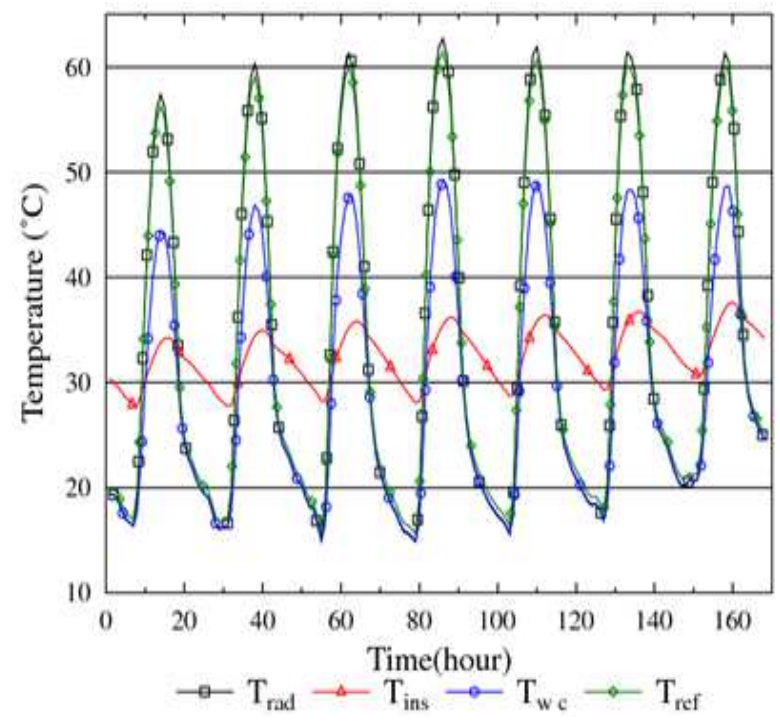

Figure 10. Roof inside face temperatures for non-architectural solution (case without attic).

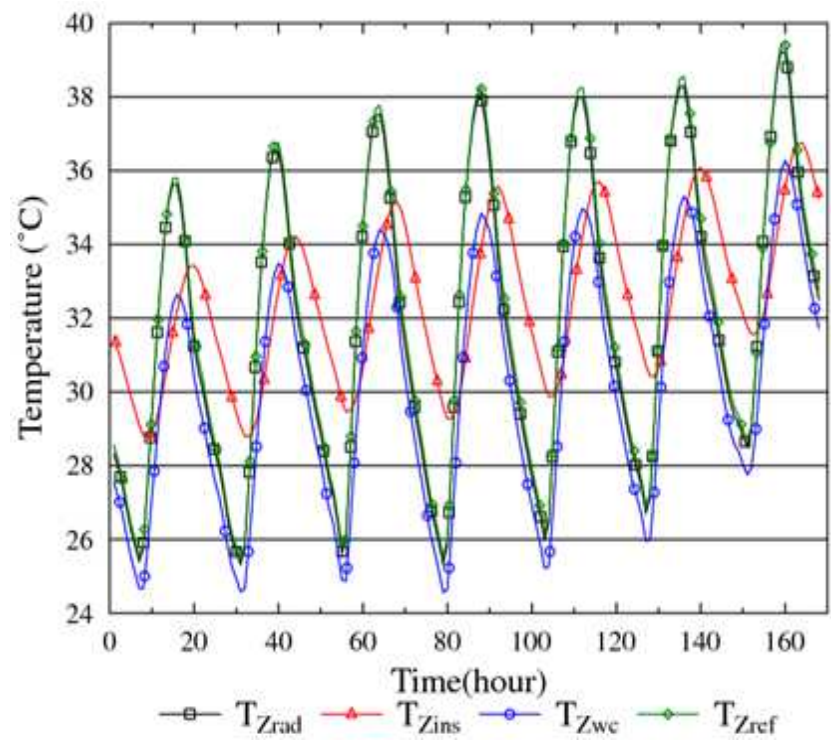

Figure 11. Zone air temperatures for non-architectural solution (case without attic).

The $5 \mathrm{~cm}$ glass fiber insulation layer has a huge impact on the ceiling (Figure10, $\mathrm{T}_{\text {ins }}$ ) and indoor air temperature (Figure $11 \mathrm{~T}_{\text {Zins }}$ ). The Insulation layer allows reducing roof temperature significantly during daytime. The decrement factor is 6.07 and the time lag $2 \mathrm{~h}$. This observation is also valuable for air temperature $\mathrm{T}_{\text {Zins }}$ because the convection heat transfer mode is affected. The weakness of insulation is its performance during nighttime when the cooling of the building by radiation with the sky is engaged. This nighttime cooling process is important for free running buildings under this climate context because it help removing the heat stored during daytime.

Low short wave absorptivity material is an interesting option. Concerning the temperature of the roof (Figure 10, $\mathrm{T}_{\mathrm{wc}}$ ), we observe a decrement factor of 1.4 and a time lag of zero. 
One can observe that the maximum zone air temperature $\mathrm{T}_{\mathrm{Zwc}}$ each day is almost equal to insulation case. In addition the white paint case allows the building to be cooled during nighttime. For these reasons this is a good solution for free running low income building where the steel inside face is one of the occupied zone surfaces.

Table 4. Decrement factor and time lag expressed relative to reference simple roof case for cases without attic

\begin{tabular}{lll}
\hline & f & $\boldsymbol{\Phi}(\mathbf{h})$ \\
\hline White paint & 1,4 & 0 \\
5cm insulation & 6,07 & 2 \\
Radiant barrier & 0,96 & 0 \\
\hline
\end{tabular}

\subsubsection{Case of Attic (Air Gap, Plywood and Ventilation)}

Simulations were done on an attic roof arrangement with non-architectural solutions. Figure 12 presents the different solutions evaluated here.

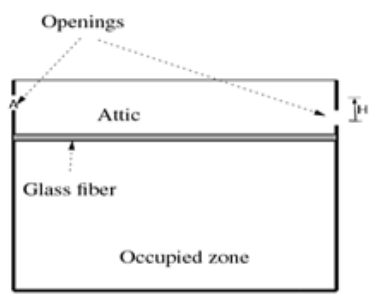

(a) Insulation case

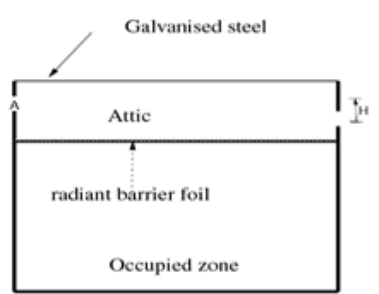

(b) Radiant barrier case

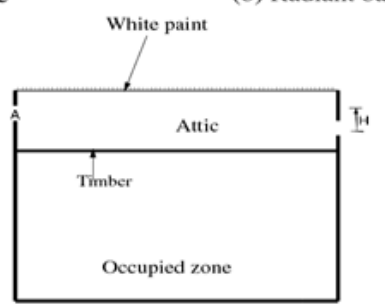

Figure 12. Illustrations of roof in attic cases.

Figure 13 and 14 present the ceiling and the occupied zone air temperature respectively. Table 5 resumes the decrement factor and the time lag expressed relative to the attic reference case for ceiling temperatures.

An improvement with radiant barrier helps to decrease maximum ceiling temperatures $\left(\mathrm{T}_{\text {Arad }}\right.$ Figure 13) with a decrement factor of 1.18, which results of lower but insignificant impact on occupied zone air temperatures $\left(\mathrm{T}_{\mathrm{ZArad}}\right.$, Figure 14) compared to the reference attic case. Here, the radiant barrier case behavior is different compared to the case without attic. The radiant barrier is more efficient when it is not in contact with occupied zone air (Table 5 and Table 4).

The insulation layer in this case impacts the maximum and minimum ceiling temperatures $\mathrm{T}_{\text {Ains }}$ (Figure 13). For occupied zone air temperature $\mathrm{T}_{\text {ZAins }}$ (Figure 14), insulation performs less than the other cases. Insulation may be interesting for HVAC controlled buildings, but less interesting for free running ones. Like in the case of section 3.4.1 low short wave absorptivity surface such as white paint, is efficient. It allows reducing temperatures in the zone by reflecting solar short wave radiation and does not affect the cooling process of the roof at night $\left(\mathrm{T}_{\mathrm{Awc}}\right.$ and $\mathrm{T}_{\mathrm{ZAwc}}$ in Figure 13 and 14).
Comparing Figure 12 and 14, it appears that for the case without attic, the building is more cooled during nighttime than the attic case. From these results of the two cases, we can conclude that high reflectance surfaces as white paint coating combined with attic is a better solution to reduce heat gain from steel roofs to the occupied zone particularly for free running buildings. But the fact that optical properties of reflective surfaces change over time, can affect their long term thermal performance.

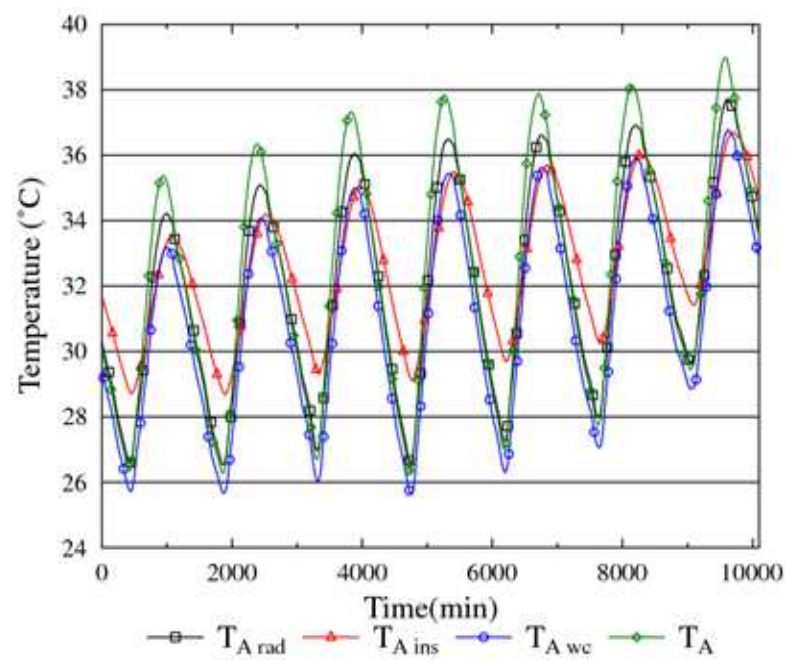

Figure 13. Ceiling face temperatures for non-architectural solution (case with attic).

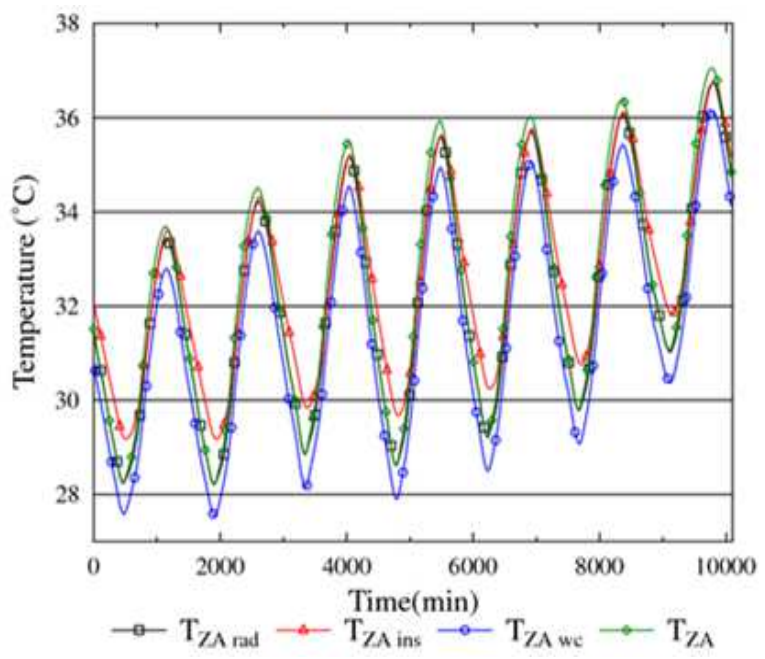

Figure 14. Occupied zone air temperatures for non-architectural solution (case with attic).

Table 5. Decrement factor and time lag expressed relative to reference attic case for cases with attic

\begin{tabular}{lll}
\hline & f & $\mathbf{\Phi}(\mathbf{h})$ \\
\hline White paint & 1,21 & 0.92 \\
5cm insulation & 2,37 & 2 \\
Radiant barrier & 1,18 & 0.87 \\
\hline
\end{tabular}

\subsection{Effect of Wind and Buoyancy Driven Ventilation}

As notified in below sections the position of the attic openings on opposite faces is often set without regard to 
desired ventilation. In order to take into account effect of stack ventilation, the height $\mathrm{H}$ is set to be $0.75 \mathrm{~m}$. Figure 15 and 16 show the results of the white coated case, when $\mathrm{H}=$ $0.75 \mathrm{~m}$ for different areas meaning that stack and wind driven ventilation are enhanced $\left(\mathrm{Q}_{\mathrm{Aref}}, \mathrm{Q}_{\mathrm{A} 0.5}\right.$ and $\left.\mathrm{Q}_{\mathrm{A} 1}\right)$. No significant differences between the ceiling temperature curves are observed $\left(\mathrm{T}_{\mathrm{Aref}}, \mathrm{T}_{\mathrm{A} 0.5}\right.$ and $\left.\mathrm{T}_{\mathrm{A} 1}\right)$ in Figure 15. The impact of ventilation trends to increase the maximum temperature during daytime and decrease the nighttime temperature.

As shown in Figure 16 despite the high rates, the ventilation does not perform well. The difference between attic zone air and outdoor air temperatures could be a reason of this low performance. During daytime, the outdoor air temperatures could be higher than the ceiling temperatures so the plywood layer can be heated by this air. The attic is not designed as a duct but as a room with $1 \mathrm{~m}$ height. In fact, we have massive construction in the attic as hollow brick walls that support the steel roof. This shape can explain the negligible impact of ventilation.

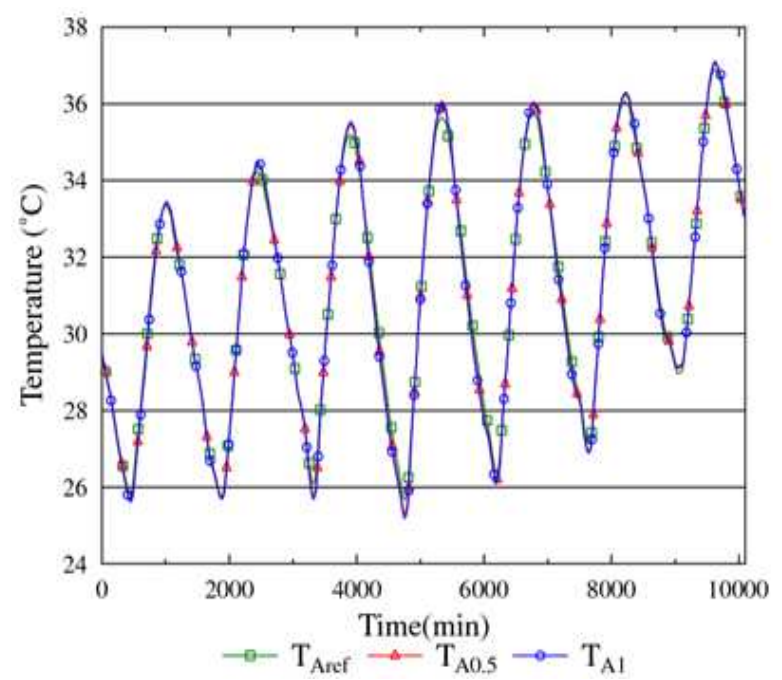

Figure 15. The ceiling temperature for different areas of openings (when $H=0.75$ ).

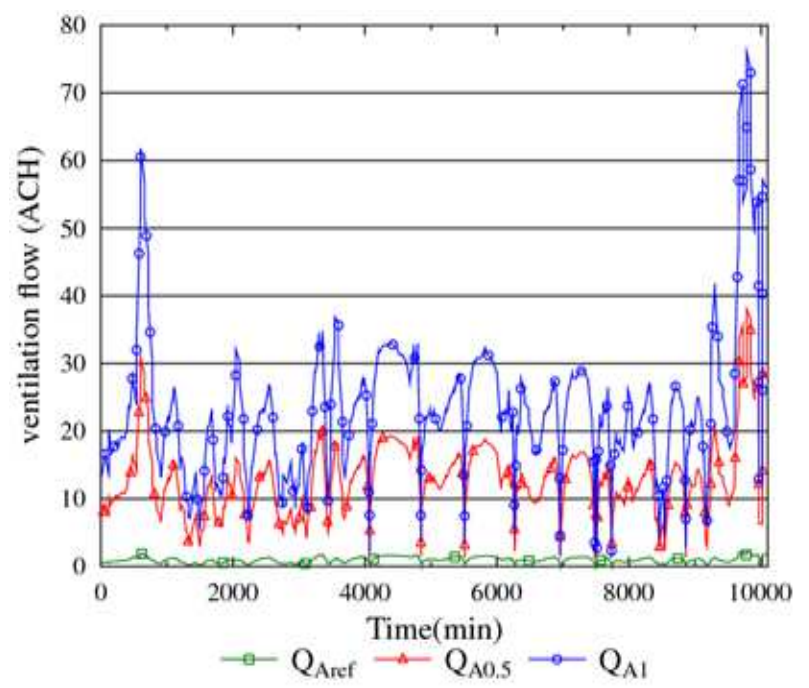

Figure 16. The attic ventilation flow rate simulated for different areas of openings (when $H=0.75$ ).

\section{Conclusion}

Steel roofing is the most adopted modern construction technology in sub-Saharan Africa. This material is responsible of a large part of heat gain in the building in these regions with tropical climate. In this paper simulations have been conducted to assess the potential of architectural and non-architectural passive cooling solutions to improve the thermal performance of the steel roof.

For the case of simple steel roof without attic, a radiant barrier reduces the radiation heat transfer from the roof temperature but does not avoid the convection heat transfer between zone air and the hot roof surface. Inside insulation of the roof leads to a reduction of temperature during daytime but increase the nighttime temperature. This solution is less interesting for free running buildings. The effect of reflective coating such as white paint gave the best performance. Reflective coating reduces temperature during the sun shining hour. Consequently, these low temperatures help to improve the cooling process of the building at nighttime.

Concerning the case of an attic, which is an architectural solution, reflective coating can improve the thermal performance. Insulation and radiant barrier lead to improvements but not interesting for free running buildings. The potential of roof ventilation as a solution have been also explored. Ventilation improvements by increasing areas and height between the opposite openings show insignificant effects on the ceiling and the occupied zone air temperatures. The design of the attic and the openings could be the reason for these low differences in ventilation cases. To assert with accuracy on ventilation, pressurized tests are necessary in order to characterize the flows in the attic. According to the results of this study we can conclude that a first solution to avoid heat gain by roof is to act on the heat radiation transfer process by using cool coated materials. But as the reflectance of reflective cool materials can change over time, this can affect the performance and it will be interesting to evaluate these changes under our tropical climate. Further works are ongoing on the building monitoring, the design and numerical models of roof in those climate contexts.

\section{Acknowledgements}

This work has received the support of the project DDC: composante 1.3.2 ecohabitat en climat sahélien.

\section{Nomenclature}

$\mathrm{T} \quad$ Roof surface temperature

$\mathrm{T}_{\mathrm{Z}} \quad$ Occupied zone air temperature

$\mathrm{T}_{\mathrm{A}} \quad$ Ceiling occupied zone side surface temperature

$\mathrm{T}_{\mathrm{ZA}} \quad$ Occupied zone air temperature for attic case

Q Ventilation flow

$\mathrm{ACH} \quad$ Air change per hour

Indices:

Aref Reference attic openings area 
A0.5 Equivalent attic openings area $A=0.5 \mathrm{~m}^{2}$

A1 Equivalent attic openings area $A=1 \mathrm{~m}^{2}$

Rad Radiant barrier case

ins Insulation case

wc White coated case

\section{References}

[1] Ajibola, K., Ventilation of spaces in a warm-humid climate-case study of some housing types. Renewable Energy, 1997. 10 (1): p. 61-70.

[2] Kisanga, A.U., The challenge faced by the building materials industries in the developing countries in the 1990s: with special reference to Tanzania. Habitat International, 1990. 14(4): p. 119-132.

[3] Moriarty, P., The case for traditional housing in tropical Africa. Habitat International, 1979. 4(3): p. 285-290.

[4] Zhai, Z. and J.M. Previtali, Ancient vernacular architecture: characteristics categorization and energy performance evaluation. Energy and Buildings, 2010. 42(3): p. 357-365.

[5] Nahar, N.M., P. Sharma, and M.M. Purohit, Performance of different passive techniques for cooling of buildings in arid regions. Building and Environment, 2003. 38(1): p. 109-116.

[6] Nahar, N.M., P. Sharma, and M.M. Purohit, Studies on solar passive cooling techniques for arid areas. Energy Conversion and Management, 1999. 40(1): p. 89-95.

[7] Akbari, H., Measured energy savings from the application of reflective roofs in two small non-residential buildings. Energy, 2003. 28(9): p. 953-967.

[8] Bozonnet, E., M. Doya, and F. Allard, Cool roofs impact on building thermal response: A French case study. Energy and Buildings, 2011. 43(11): p. 3006-3012.

[9] Hernández-Pérez, I., et al., Thermal performance of reflective materials applied to exterior building components-A review. Energy and Buildings, 2014. 80(0): p. 81-105.

[10] Synnefa, A., M. Santamouris, and H. Akbari, Estimating the effect of using cool coatings on energy loads and thermal comfort in residential buildings in various climatic conditions. Energy and Buildings, 2007. 39(11): p. 1167-1174.

[11] Sanjai, N. and P. Chand Passive cooling techniques in buildings: past and present a review. ARISER 4, 2008: p. 37-46.

[12] Susanti, L., H. Homma, and H. Matsumoto, A naturally ventilated cavity roof as potential benefits for improving thermal environment and cooling load of a factory building. Energy and Buildings, 2011. 43(1): p. 211-218.
[13] Haberl, J.S.C., S., Literature Review of Uncertainty of Analysis Methods (Cool Roofs), Report to the Texas Commission on Environmental Quality. 2004.

[14] Özdeniz, M.B. and P. Hançer, Suitable roof constructions for warm climates - Gazimagusa case. Energy and Buildings, 2005. 37(6): p. 643-649.

[15] ASTM, ASTM: C1313/C1313M-10. Standard Specification for Sheet Radiant Barriers for Building Construction Applications in 2010.

[16] Mitchell, R., et al., RESFEN 3.1: A PC Program for Calculating the Heating and Cooling Energy Use of Windows in Residential Buildings. 1999.

[17] Iwaro, Joseph, and Abraham Mwasha. 2010. "A review of building energy regulation and policy for energy conservation in developing countries." Energy Policy 38 (12) : 7744 - 7755. Special Section : Carbon Reduction at Community Scale.

[18] Crawley, D.B., et al., EnergyPlus: creating a new-generation building energy simulation program. Energy and Buildings, 2001. 33(4): p. 319-331.

[19] Perez, R., et al., Modeling daylight availability and irradiance components from direct and global irradiance. Solar Energy, 1990. 44(5): p. 271-289.

[20] EnergyPlus, EnergyPlus engineering reference: the reference to EnergyPlus calculations, 2013, Berkeley, CA: Ernest Orlando Lawrence Berkeley National Laboratory.

[21] F. Allard, M.S., Natural Ventilation in Buildings: A Design Handbook. Vol. Earthscan. 1998: James \& James (Science Publishers) Ltd.J. Clerk Maxwell, A Treatise on Electricity and Magnetism, 3rd ed., vol. 2. Oxford: Clarendon, 1892, pp.68-73.

[22] ASHRAE, Chapter 24 airflow around buildingsS, in ASHRAE Handbook - Fundamentals (SI Edition)2009, American Society of Heating, Refrigerating and Air-Conditioning Engineers, Inc.

[23] Awbi, H.B., Design considerations for naturally ventilated buildings. Renewable Energy, 1994. 5(5-8): p. 1081-1090.

[24] Modelisar, Functional Mock-up Interface for Co-Simulation Modelisar (ITEA 2 07006). 2010.

[25] Nouidui, T., M. Wetter, and W. Zuo, Functional mock-up unit for co-simulation import in EnergyPlus. Journal of Building Performance Simulation, 2014. 7(3): p. 192-202.

[26] ASHRAE, 2009 ASHRAE Handbook Fundamentals, Chapter 13: Indoor environmental modeling., 2009, ASHRAE (American Society of Heating, Refrigeration and Air-Conditioning Engineers). 